\title{
The role of sound symbolism in protolanguage: Some linguistic and archaeological speculations*
}

\section{Introduction}

Sound symbolism seems to be a good candidate for a linguistic universal. It can be observed in many languages of the world. ${ }^{1}$ In addition, no known present or past language seems to be completely based on sound-symbolic associations, since such associations are very limited and cannot be used to create a large vocabulary. Nevertheless, the persistence of this feature in the languages of the world and its alleged naturalness could be easily explained if we assume that sound-symbolism is a remnant of some earlier stage of human language. In this paper, I will first sketch the role of sound symbolism in the origins of vocabulary following the proposals made by M. Swadesh in the early seventies and then I will provide linguistic and archaeological data suggesting the important role of sound symbolism in the final stages of human symbolic mind evolution. In order to do this I will reinterpret some of the so-called global etymologies proposed by Bengtson and Ruhlen 1994 as instances of sound-symbolic associations, and I will relate the entities denoted by these etymologies to some of the engraved or painted symbols characterizing the artistic activity of the Upper Paleolithic period.

See the general surveys in Ultan 1978, Voeltz \& Kilian-Hatz 2001, Hinton, Nichols \& Ohala 1994 and Bartens 2000. 


\section{Sound-symbolic aspects of protolanguage}

In spite of the widely accepted view maintaining that human speech is unique and cannot be assimilated to vocal animal communication, Swadesh (1971: 158) proposed that there is some sort of evolutionary continuity between animal cries and human language. Although this view is not generally accepted in contemporary linguistics, it has been submitted to a partial reconsideration in recent research. In their modern review of the evolutionary basis of human language, Hauser, Chomsky \& Fitch say that "the available data suggest a much stronger continuity between animals and humans with respect to speech than previously believed" (2002: 1574). This partial continuity can be located in certain marginal aspects of fully developed modern human languages, such as exclamations and interjections. Following Swadesh, exclamations and interjections present in all known human languages, are remnants of an early stage in vocal communication out of which human modern speech emerged. This author distinguishes (1971: 179) two main levels: an instinctive-intuitive level found in all animals and the formal, conventional level found only in humans. ${ }^{2}$ The second level developed out of the first by means of two main mechanisms:

a) The differentiation of demonstrative (pointing) signals from attention-calling ones.

b) The advanced use of sound imitation in play and in expression.

In what Swadesh calls eoglottic period, the earliest stage in the evolution of human language, the imitative and the exclamation systems began to separate. The exclamation system split into two modules: a purely expressive paradigm and an attention-calling or demonstrative level. This is shown in the following diagram:

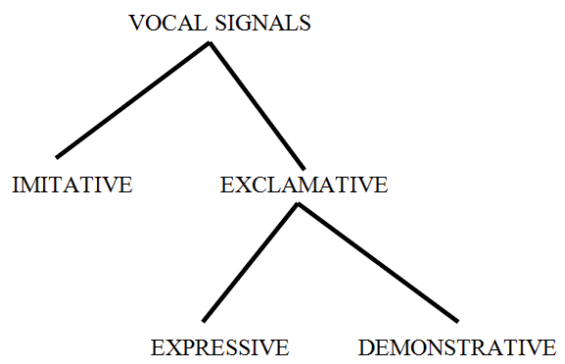

Figure 1.

2 Burling 2005: 105-120 offers an updated account of the differences and similarities between animal and human communication. 
Imitation has to do with onomatopoeic sound symbolism or phonosymbolism. One more or less universal example of this type of imitative vocal signs is the expression $m a$ associated with maternity and suckling, since babies make nasal sounds in the midst of suckling. Another example is the phono-symbolic association between nasal phonemes and demonstratives and negation. Swadesh says that this could be due to the fact that both are based on grunts.

Manual and vocal gestures played an important role in the disambiguation of demonstratives. Swadesh observes that vocal speech gestures would have played a role in the use of the demonstrative grunts: "pouting gives the lips a shape adequate for pointing, and the tip of the tongue can also serve as a pointer" (1971: 194).

In this early eoglottic stage, the different articulatory positions of the vocal organs had their own symbolic significance. In this intuitive language, stops reflect a sharp impact, nasals represent resonant vibrations and fricatives echo "the continued rubbing and ongoing sounds of a nonresonant vibratory character. The vocalic timbres are usually associated with shapes corresponding to the form that the mouth must assume to produce each of them" (1971: 200).

The most important innovation in the transition from the eoglottic to the paleoglottic period was that imitative sounds were used not only to portray a particular noise, but also to symbolize the action that produced it and the shape of the object involved.

This means that sound symbolism of the pheno-mimic type (as phonetic representations of phenomena perceptible by non-auditory senses) develops out of that of the phono-mimic type (as phonetic representations of sound phenomena).

Swadesh establishes the following list (1971: 208) of pheno-mimic sound symbolism:

a) Stops represent hard impact, nasals soft impact or resonant vibration, continuants free vibration.

b) Vowels indicate shape.

c) Labials $(p, m)$ give the effect of flat surfaces slapping together, dentals $(t, n)$ the contact of a point, velars $(k, n g)$ that of blunt objects, sibilant $(s)$ liquid or sliding contact.

Let us introduce now a couple of examples taken from Swadesh (1971: 209) illustrating these sound-symbolic associations of the pheno-mimic type: 
tek 'from pointed to blunt' (or the opposite)

pek 'flat base to blunt point'

pet 'flat base to pointed tip'

The evolutive transition from phono-mimic to pheno-mimic sound symbolism can be made sense of if we turn our attention to the theory of the evolution of the human mind proposed by Steven Mithen (1996). In this theory, the hominids developed specialized modules of the mind for different purposes in a series of evolutionary steps, characterized in the following way.

\section{Three phases of the development of modern human mind}

1. The mind is dominated by general intelligence.

2. Domain-specific modules supplement general intelligence, each working independently in isolation.

3. Domain-specific modules are working together with a seamless flow of information across different domains.

The domain-specific intelligences included are technical intelligence, social intelligence and natural history intelligence. The third stage is characterized by an intensive cognitive fluidity. The key to cognitive fluidity is the ability to use information from one domain in a new and different domain. I think that the use of sounds to denote non-auditory aspects of the world is a main symptom of this human cognitive fluidity, in which a representation of a sound is used in a different domain of perception. The transition from phono-mimic sound symbolism, in which a sound is used to reproduce another sound, to pheno-mimic sound-symbolism, in which a sound is used to characterize a visual shape, could be a manifestation of the cognitive fluidity proposed by Mithen. Metaphor can also be viewed as further demonstration of this same ability. Indeed, there are clearly metaphoric aspects in sound symbolism. For example, vowel quality can be used for size symbolism as the pairs [i] / smallness and [a] /largeness show (Ultan 1978). ${ }^{3}$ In this case, a metaphorical association between visual and aural images can be assumed. In the following sections of the present paper, I will make some linguistic and archaeological speculations concerning some of the earliest recoverable sound symbolic associations characterizing the pheno-mimic stage of sound symbolism in the passage from the paleoglottic to the neoglottic period, the period in which modern human language developed.

3 This association is not universal as demonstrated by Diffloth 1994. 


\section{Sound-symbolic bases of global etymologies}

Global etymologies are roots that seem to be attested in most language families all over the world. They were proposed in the early nineties by Bengtson \& Ruhlen (1994). In that paper, the authors reconstruct 27 etymologies on the basis of an extensive comparison of the language families of the world. These reconstructions are based on words from languages belonging to different linguistic stocks and presenting a resemblance both in form and meaning. In order to illustrate this point, I include some examples taken from one of the global etymologies proposed by these authors:

\section{Global etymon: TIK 'finger, one'4}

Niger-Congo: Tonga: ticho 'finger'

Afro-Asiatic: Oromo: toko ' 1 '; Hausa tak 'only 1'

Indo-European: Latin $\operatorname{dig}(-i t u s)$ 'finger'

Túrquico: Chuvash tek 'only, just'; Turkish tek 'only'

Eskimo-Aleut: Greenlandic: $t i k(-i q)$ 'index finger'

Amerind: Mohawk tsi'er 'finger'; Karok: tik 'finger, hand'; Mangue: tike '1'; Kukura: tikua 'finger' ; Chibcha: ytiquyn 'finger'

These global etymologies have been strongly criticized by historical linguists for not abiding by the usual methods of linguistic reconstruction, ${ }^{5}$ since they are based on loose phonetic resemblances and not on specific and regular phonetic laws as those discovered in the study of IE (Indo-European) languages and languages from other linguistic families. In the *tik example presented above, a general resemblance can be observed in the words used to reconstruct this etymon that could be stated as $t V k$, in which $t$ is a dental stop, $\mathrm{V}$ is a palatal high vowel and $k$ is a velar stop. Nevertheless, the authors do not provide a strict set of phonetic correspondences characterizing the different language families used in the reconstruction process. In IE linguistics we know that the comparison between English father and Spanish padre 'father' evidences a correspondence [p]/ [f] that can be traced back to protoGermanic and proto-Italic and that can be observed in other Germanic and Italic words. As Campbell (2008: 81) points out, English much and Spanish mucho 'much' are almost identical from a phonetic and semantic points of view. Nevertheless, these word are not genetically related to each other, since Spanish mucho comes from Latin multus 'much, many' and English

4 The protoworld *tik proposed by Bengtson \& Ruhlen is reminiscent of the tek phenomime proposed by Swadesh, although they are not related to each other.

See Campbell 2008 and references therein. 
much comes from Germanic *mik-ila 'great, much'. The latin word is related to IE *mlto 'great, strong', whereas the Germanic word is related to IE *meg 'great'. This example demonstrates that a sheer phonetic/ semantic coincidence does not guarantee a prehistoric relationship between two or more lexical items. Much more evidence is needed concerning systematic phonetic-correspondences between languages or languages families. Thanks to these correspondences non evident historic relationship between lexical items can be discovered. For instance, we know that English two and Armenian yerku 'two' are historically related, although there is no phonetic similarity between them.

If global etymologies do not necessarily establish genuine genetic relationships, what could be the cause of the phonetic/semantic resemblances between so many lexical items from languages all over the world?

Campbell (2008:88-90) reinterprets some of the global etymologies as instances of sound symbolic associations. In particular, this author thinks that a few of the proposed global etymologies could be interpreted as onomatopoeic words. As onomatopoeia is based on sound-imitation, it is expected that different languages present a similar phonetic rendition of the same natural sound. Campbell notes that H. H. Hock (1993) interprets in this way the *maliq'a 'breast, suckle, nurse' global etymology proposed by Bengtson \& Ruhlen. The natural sounds mimicked in this case are the noises children make when nursing, sucking. Following these suggestions, I will extend the sound symbolic reinterpretation of global etymologies in two ways. First, I will apply this reinterpretation to new global etymologies and, secondly, in order to do this, I will consider not only onomatopoeia but also pheno-mimic sound symbolism.

I will pay attention in this paper to two of the global or world etymologies proposed by Bengston \& Ruhlen (1994): *puti 'vulva' and *tik 'finger, one.'

Following the suggestions made by Hock, Campbell and others I think that these supposed etymons are amenable to a sound-symbolic interpretation explaining their ubiquity. This interpretation cannot be limited to onomatopoeia, but must also be extended to other instances of soundsymbolism such as pheno-mimic sound-symbolism, consisting in phonetic representations of phenomena perceptible by non-auditory senses. Once this is done, a more principled and insightful explanation can be offered for some of the global etymologies proposed by Bengtson \& Ruhlen.

Two of the three etymons I consider in this paper, *puti and maliq'a, concern the sphere of nature and are related to certain body parts and basic biological activities of human beings. The alleged global etymology * $t i k$ 'finger, one' is also related to the cultural or symbolic sphere and denotes a body part 
that is frequently used for pointing, perhaps one of the most basic and ancient semiotic activities. It is reasonable to think that the actions and entities related to these etymons are good candidates for ancient sound-symbolic associations, since they are related to very basic aspects of human society.

Only one of these etymons (*maliq'a) can be interpreted as a phonomimic sound symbolism -that is, as an onomatopoeia- in a more or less straightforward way, as suggested by Hock and Campbell. The others do not seem interpretable in these terms. Nevertheless, this does not mean that they do not convey sound-symbolic associations. Is there any clue of a sound-symbolic interpretation for these reconstructed etymons that can be used to explain the undeniable similarities of the actual words from the five continents on which they are based? Although there is not a universally accepted view concerning this particular point, I think that there are proposals that can suggest such clues.

Following Swadesh, the suggestions summarized in the second section of this paper concerning certain sound symbolisms of the pheno-mimic type, the etymons, *puti 'vulva' and *tik 'finger, one', could be interpreted in pheno-mimic terms.

Let us examine *puti. This etymon has a labial stop followed by a velar labialized vowel. Labial stops such as [p] or [m] are pronounced by putting together the lips and the velar vowel $[\mathrm{u}]$ is usually pronounced by protruding the lips. Therefore, there seems to be a natural pheno-mimic association between syllables such a [pu] and [mu] and the human mouth. Indeed, we can find several etyma in different language families with the meaning 'mouth' or 'lip' and with that phonetic configuration. As pointed out in Moreno Cabrera (2004: 138) in Germanic, a *munba 'mouth' (cfr. German Mund 'mouth') lexeme has been reconstructed (Kluge 1995: 574). In IndoEuropean, a lexeme *bu 'lip, to kiss' has been proposed (Décsy 1991: 74). In proto-Bantu an etymon *-mùà 'mouth' has been reconstructed (Guthrie 1970: 18). In Telugu, a Dravidian language (Southern India), we have muti 'mouth' and in Indonesian we have mulut 'mouth'.

All these coincidences point to a pheno-mimic association $\mathrm{pu} / \mathrm{mu}$ with 'mouth' and 'lip'. Now, the use of the *puti word to denote the female outer sexual organs, could be seen as a metonymic derivation of the basic pheno-mimic relation pu/lips plus an analogical relation between vulva and mouth. If this suggestion seems reasonable, the second syllabic component of the *puti etymon, that is the [ti] syllable, could also be interpreted from a pheno-mimic point of view. Swadesh (1972: 208) proposed that dentals ([t] and $[\mathrm{n}]$ ) give the effect of the contact to a point. Therefore, the phonetic configuration of the *puti global etymology can be interpreted as a pheno- 
mimic representation of an abstract pointed schematic image symbolizing the feminine sex: an inverted triangle with a middle vertical line. This sign is the classic pubic triangle well attested in prehistoric art. ${ }^{6}$

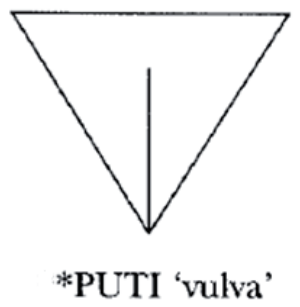

Figure 2.

The pheno-mimic relation observed in this picture can be schematized as follows:

$[\mathrm{pu}]=$ bilabial stop+rounded back vowel / 'flat surfaces in contact' [ti] = alveodental stop+hugh unrounded front vowel/ 'convergence to a point.'

In addition, the phonetic configuration of the *tik global etymon can be accounted for in the same pheno-mimic terms. Swadesh proposed tek suggests 'from pointed to blunt (or the opposite). This is the form of a fist with an extended index finger, usually used for pointing:

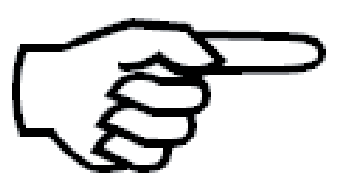

Figure 3.

As suggested in Moreno Cabrera (2004: 140), this figure can be related to the pubic triangle by means of a 90 degree rotation:

${ }_{6}$ See, for example, the La Ferrassie Aurignacian vulvas (Leroi-Gourhan 1958). 


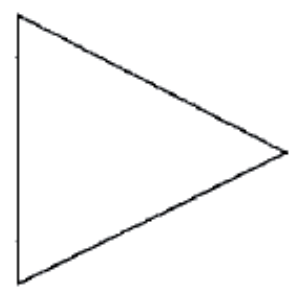

\section{*TIK}

Figure 4.

This geometrical relationship would explain the recurrence of the [ti] syllable in the two etymons considered here.

In conclusion, it can be argued that the phonetic coincidences observed in many words denoting the feminine sexual organ and the human finger used for pointing and for denoting the numeral 'one' can be explained on the basis of some more or less natural sound-symbolic associations. Although these sound-symbolic words do not justify the reconstruction of putative etyma pertaining to an alleged proto-world language, it can be assumed that the sound-symbolic relationships on which they seem to be based are indeed very ancient and constitute a remnant of an early phase in the development of the expressive capacities of sound on which human language developed, as suggested in the second section of this paper. Note that I am not stating that there once existed a proto-world language having a *puti and a *tik word as lexical elements; instead, a parallel convergent change driven by natural sound symbolic associations could be the explanation for the ubiquity of the corresponding sound-meaning association. What I am suggesting is that the frequency and extension of such symbolic associations point to a primitive or basic mechanism of lexicon development and not to the spread by inheritance of a particular symbolic association coming from a putative proto-world mother language.

\section{The dating of the phono-symbolic associations suggested by global etymologies}

In her suggesting overview of the origin and dispersal of languages, J. Nichols (1998: 136-139) proposed a simple method for dating ancient linguistic historical relationships and for estimating the linguistic age of the world. On the basis of what we know about the evolution of linguistic families and linguistic stocks since a very distant past, it has been established that each 6.000 years an average of 1,5 new linguistic branches are produced. Nichols 
takes advantage of this fact in her proposal for dating the age of linguistic families that are supposed to be historically related. This is done by dividing the number of stocks by 1.5 , dividing the result by 1.5 , and so on until the result is less than 2 . Then, the number of divisions performed is multiplied by 6.000 . The result represents the time that has passed since the initial steps towards the splitting of an ancient language into the different language families. ${ }^{7}$ Following this tentative method, it could be said that a set of linguistic families comprising 12 elements and considered as descendants of a very ancient language has an antiquity of about 42.000 years. We need to divide 12 by 1,5 seven times in order to obtain a result lesser than 2 ; so if we multiply 7 by 6000 we obtain 42.000 .

Nichols gives us the following table for making the necessary calculations:

\begin{tabular}{|c|c|}
\hline Number of stocks & age in years \\
\hline 2 & 6.000 \\
\hline $3-4$ & 12.000 \\
\hline $5-6$ & 18.000 \\
\hline $7-10$ & 24.000 \\
\hline $12-15$ & 30.000 \\
\hline 20 & 36.000 \\
\hline 40 & 48.000 \\
\hline
\end{tabular}

This tentative method can be used to guess at the possible antiquity of the alleged global etymologies proposed by Bengtson \& Ruhlen. ${ }^{8}$ Let me apply it to the etyma considered in this paper. The *maliq'a 'to suck(le), nurse, breast' etymology is attested in 7 language families, and therefore its antiquity can be estimated in about 24.000 years. The *puti 'vulva' etymology has been based on 15 language families; this gives us an antiquity of 30.000 years and, finally, the *tik 'finger, one' global etymology has been attested in 20 language families; this gives us the biggest figure: 36.000 years. I summarize the results in the following table:

As Nettle (1999: 120) notices, the assumptions on which this simple method for linguistic dating are based are debatable and need further empirical justification. Nettle himself has sketched an alternative mathematical model solving some of the alleged flaws and inadequacies of Nichols' proposals (Nettle 1999: 122-126).

Although the figures given are exact, both the method and the objects to which it is applied (the global etymologies) are rather speculative and rough. For this reason, these results can only be seen as a very tentative guess. 


\begin{tabular}{|c|c|c|}
\hline Etymon & number of stocks & antiquity \\
\hline${ }^{*}$ maliq'a & 7 & 24.000 \\
\hline${ }^{*}$ puti & 15 & 30.000 \\
\hline${ }^{*}$ tik & 20 & 36.000 \\
\hline
\end{tabular}

Although the method I have described here is designed for determining the possible antiquity of a set of linguistic stocks considered as descendants from a linguistic ancestor, the observed results could be used to estimate the possible antiquity of the sound-symbolic associations I am considering in this paper. The fact that the same sound-symbolic association is attested in 10 or 20 linguistic families could be interpreted as a signal of the genuine antiquity of that association. And that antiquity can be said to be similar to that of the putative ancestor of the families involved, if any indeed existed.

\section{Sound-symbolism and Upper Paleolithic art}

Since languages do not fossilize, it is extremely difficult to propose any correlation between archaeological remains and languages; it is even more difficult to assume any plausible direct correlation between archaeological findings and the possible stages of human language creation and evolution.

Nevertheless, the speculations of the previous paragraphs can give us some clues concerning a possible linguistic/archeological correlation, since the calculated antiquity of the three global etymologies considered in this paper coincides in a very precise way with the archaeological period in which the first unequivocal, systematic and full-fledged manifestations of human symbolic activity are found. ${ }^{9}$ Between 30.000 and 10.000 years b. p. there is the Upper Paleolithic age. Some important remnants of human symbolic activity can be located in the Aurignacian \& Gravettian periods of this age. I will consider here the female representations characteristic of this period, notably, the engraved or painted representations of the female sexual organ and the well know Venus figurines.

In the following illustration, we can see some of the most typical drawings depicting the female sex, characteristic of this period, as collected by Leroi-Gourhan (1958: 525):

9 This is a controversial issue. Some authors (Noble \& Davidson 1996: 217) maintain that the arrival of modern humans in Australia some 60.000 years b.p., is the earliest archaeological evidence of human behavior; other authors propose a much earlier date (see the detailed review in McBrearty \& Brooks 2000). 


\section{(1) $\nabla \nabla \vee v \otimes \Delta \Delta \mathbb{A}$}

Figure 5 .

It is crucial to pay attention to the schematic and geometrical character of these representations. These are idealized or abstract representations that, in my view, can be said to denote the visual side of the pheno-mimic sound symbolic associations I have discussed in the preceding sections. These visual representations could be related to the *puti etymon since the archaeological and linguistic dates coincide in an almost perfect way. Of course, the dating of the *puti pheno-mime is rather speculative. Moreover, I am not postulating the existence of an original *puti etymon as Bengtson \& Ruhlen (1994) do. What I wish to suggest here is that the symbolic pheno-mimic association exemplified by the pair *puti/ 'vulva' is indeed very ancient and therefore is a good candidate for a naturally recurrent symbolic association that appeared already in the very early stages of modern language evolution. As a consequence, it should be dated at least at the most ancient period of fully developed modern human language consistent with what we know about the linguistic composition of the world. ${ }^{10}$

These visual representations of the female sexual organ may be the origin of certain more recent signs and icons related to the woman and to the feminine gender. In the following figure, taken from Desfayes (2005), some of these representations are presented and related to some of the historically attested female symbols.
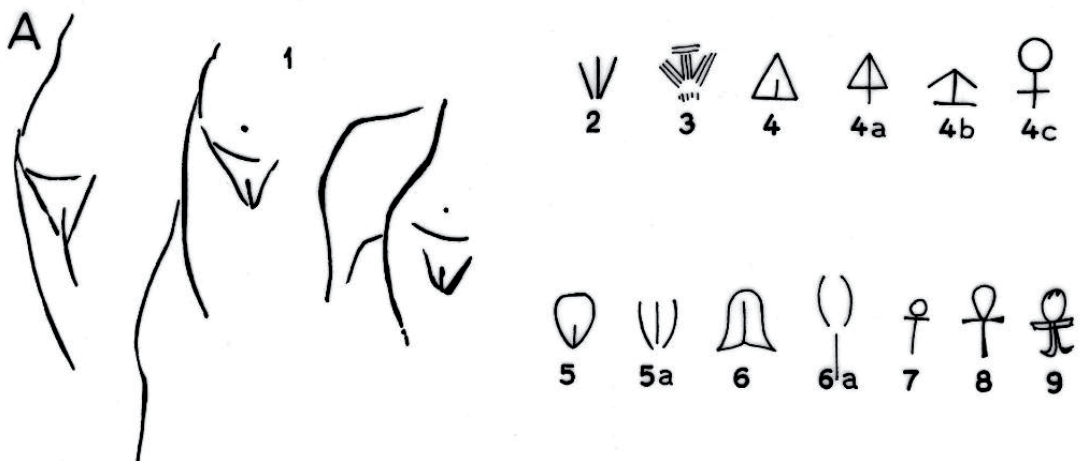

Figure 6. Figures $A$ show the transition from a realistic representation of women's bodies (Angles-sur-l'Anglin, West of Poitiers) to the symbol + . 1. Female

10 This period could be estimated in between 70.000 years and 120.000 years b.p., following Nichols 1998: 138-139. 
group from Angles-sur-l'Anglin, west of Poitiers (France). 2. Altamira (Spain). 3. Fond-de-Gaume (France). 4, 4a. La Mouthe (France). 4b. Fondde-Gaume (France). 4c. Ideogram representing the modern female symbol. 5. Marsoulas (France) ${ }^{11}$ 6, 6.a. Niaux (France). 7. Egyptian hieroglyph knh and " $z$ " Linear B. 8. Egyptian ankh, symbol of fertility. 9. Hittite symbol of life.

The Upper Paleolithic age, especially in the Gravettian period, is the time in which almost all the Venus figurines are dated. In her review of this subject, K. D. Jennet states that "the most often pictured figurines are those that are carved so that certain parts of the anatomy are emphasized while others are deliberately neglected. The hair-styles, breasts, abdomen, hips, thighs and vulva are often exaggerated while the extremities (heads, arms, hands, legs, and feet) and facial features are often lacking" (Jennet 2008: 5). In these statuettes we can again find representations of the female genitals. This could be a further clue for the symbolic function of these representations, although the exact interpretation is still a matter of debate between scholars. The following figures show the famous Venus of Willendorf and the Ostrava Venus: two paradigmatic examples of this type of statuettes in which the pubic triangle is clearly carved.

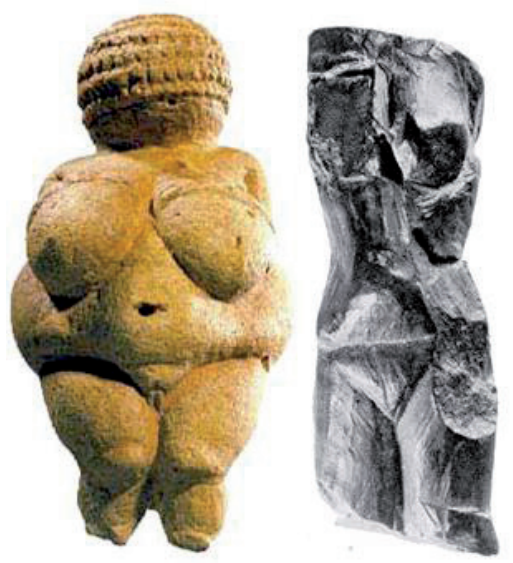

Figure 7.

This prehistoric symbolism seems to have paved its way up to the historic times. Desfayes (2005) argues that these representations of the female sex, one of the first expressions of art in Europe, could be the antecedent of a series

11 Desfayes (2005) does not give the reference of 5a in figure 6. 
of modern symbols that have been transmitted through many centuries up to the present day, most notably of the female $O$ sign.

In addition, there is at least one historical attestation of the pheno-mimic relation postulated here to explain the ubiquity of the * puti / 'vulva' symbolic associations. As we have seen in this paper, this is the sound symbolic relation between the pubic triangle and a phonetic configuration with a bilabial stop, a back rounded vowel followed by a dental stop.

We can witness exactly this type of pheno-mimic sound symbolism if we pay attention to the pictographic symbol for woman (a pubic triangle) of the Uruk IV tablets that serves as antecedent for the cuneiform spelling of the Sumerian word munus ${ }^{12}$ with a phonetic configuration predicted by Swadesh with a bilabial stop $([\mathrm{m}])$ and an alveo-dental stop ([n]) parallel to the reconstructed global root *puti in which we find a similar phonetic form (a bilabial [p], a rounded back vowel plus an alveo-dental stop[t]):

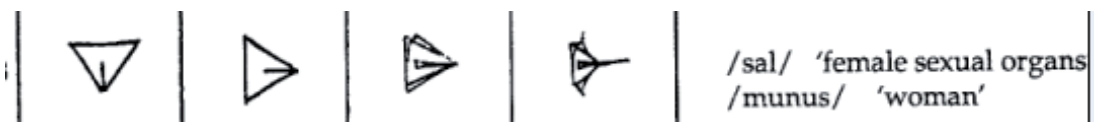

Figure 8 .

\section{Conclusion}

In this paper, I have tried to clarify the role of sound symbolism in the early development of human language vocabulary The mimicking of natural sounds by means of an articulated language, producing onomatopoeic sound-symbolism could be considered as one first stage in human language vocabulary evolution. The following step consists in using sounds to symbolize phenomena perceptible by non-auditory senses. Sound symbolization began to relate certain sounds to the visual aspects of objects such as size or shape or to certain aspects of actions and states. This is called pheno-mimic sound-symbolism. The transition from phono-mimic or onomatopoeic sound symbolism to pheno-mimic sound representations can be related to the stage of human mind evolution proposed by S. Mithen (1996) in which domain-specific modules work together with a seamless flow of information across different domains. This is called cognitive fluidity. This cognitive fluidity could be responsible for the connection between different cognitive abilities: visual processing, auditory processing and the socialsemiotic activity of linguistic symbolism.

12 See Jiménez Zamudio 1998:123; Coulmas 2003: 45; Michalovski 2004: 31 and Rogers 2005: 89 . 
This proposal is followed by some linguistic and archaeological speculations concerning the earliest attested sound-symbolism in human languages and its possible relations with certain manifestations of Paleolithic art. On the linguistic side, I have suggested that some of the world etymologies proposed by Bengtson \& Ruhlen (1994) can be reinterpreted in terms of a pheno-mimic association. On the archaeological side, I have speculated on a possible symbolic relationship between the world etymon *puti and the Upper Paleolithic schematic representations of the female outer sexual organ. I have also shown that there is at least one language of antiquity, Sumerian, in which such ancient symbolic relationship has been preserved in its written form.

\section{Acknowledgments}

Thanks are due to one of the editors (SW) and to two anonymous reviewers for useful criticism and comments. All the speculations made in this paper are the sole responsibility of the author. This paper reports on the research project "Typological and Evolutive Aspects of Linguistic Complexity" (HUM2006-05118) financed by the Ministerio de Educación y Ciencia, Spain and the FEDER funds.

\section{References}

Bartens, A. (2000). Ideophones and sound symbolism in atlantic creoles. Helsinki: The Finnish Academy of Science and Letters.

Bengtson J. D. \& Ruhlen, M. (1994). Global Etymologies. In M. Ruhlen (Ed.), On the Origin of Languages. Studies in Linguistic Taxonomy (p. 277-366). Stanford: Stanford University Press.

Campbell, L. (2008). What can we learn about the earliest human language by comparing languages known today?. In B. Laks (Ed.), Origin and Evolution of Languages. Approaches, Models, Paradigm (p.79-111). London: Equinox.

Coulmas, F. (2003). Writing Systems. An introduction to their linguistic analysis. Cambridge: Cambridge University Press.

Décsy, G. (1991). The Indoeuropean protolanguage: a computational reconstruction. Bloomington: Eurolingua.

Desfayes, M. (2005). Origin of male and female symbols. Rivista di Biologia / Biology Forum 98, 197-202. (http://www.michel-desfayes.org/?p=15).

Diffloth, G. (1994).“i: big, a: small”. In Hinton, Nichols \& Ohala (eds.) 1994: 107114 
Guthrie, M. (1970). Comparative Bantu: an introduction to the comparative linguistics and prehistory of the Bantu languages. Vol 4. Amersham: Gregg International Publishers.

Hinton, L., Nichols, J. \& Ohala, J. J. (Eds.) (1994). Sound symbolism. Cambridge: Cambridge University Press.

Hauser, M. D., Chomsky, N. \& Fitch, T. (2002). The faculty of language: What is it, Who has it, and How Did it evolved. Science, 298, 1569-1579.

Hock, H. H. (1993). Swallow tales: chance and the world etymology MALIQ'A 'swallow, throat'. Chicago Linguistic Society, 29, 215-219.

Jackendoff, R. (2002). Foundations of Language. Brain, Grammar, Evolution. Oxford: Oxford University Press.

Jennet, K. D. (2008). Female figurines of the upper paleolithic. Texas State Univerisity Honor's Thesis.

Jiménez Zamudio, R. (1998). Gramática de la lengua sumeria. Madrid: Ediciones Clásicas.

Kluge, F. (1995). Etymologisches Wörterbuch der deutschen Sprache. Berlin: Walter de Gruyter.

Leroi-Gourhan, A. (1958). Répartition et gropement des animaux dans l'art parietal paléolithic. Bulletin de la société préhistorique française, 55, 9, 515-528.

Leroi-Gourhan, A. (1967). Treasures of prehistoric art. New York: Abrams.

McBrearty, S. \& Brooks, A. S. (2000). The revolution that wasn't: a new interpretation of the origin of modern human behavior. Journal of Human Evolution, 39, 453-563.

Michalovski, P. (2004). Sumerian. In R. D. Woodard (Ed.), The Cambridge Encyclopedia of the World's Ancient Languages (p. 19-59). Cambridge: Cambridge University Press.

Mithen, S. (1996). The Prehistory of the Mind. The Cognitive Origins of Art, Religion and Science. London: Thames \& Hudson.

Moreno Cabrera, J. C. (2004). Voces ancestrales. Paleolexicología, semántica diacrónica y arte prehistórico. In M. Villayandre Llamazares (Ed.), Actas del V Congreso de Lingüistica General. Vol 1. (p. 123-148). Madrid: Arco.

Nettle, D. (1999). Linguistic Diversity. Oxford: Oxford University Press.

Nichols, J. (1998). The origin and dispersal of languages: linguistic evidence. In N. G. Jablonski y L. A. Aiello (Eds.), The origin and diversification of Language (p.127-170). San Francisco: California Academy of Sciences.

Noble, W. \& Davidson, I. (1996). Human evolution, language and mind. Cambridge: Cambridge University Press.

Rogers, H. (2005). Writing Systems. A Linguistic Approach. Oxford: Blackwell.

Swadesh, M. (1971). The Origin and Diversification of Language. London: Routledge \& Kegan Paul.

Ultan, R. (1978). Size-sound symbolism. In J. H. Greenberg (Ed.), Universals of Human Language. Volume 2. Phonology (p. 525-568). Stanford: Stanford University Press.

Voelts, F. K. E. \& Kilian-Hatz C. (eds.) (2001). Ideophones. Amsterdam: John Benjamins. 